\title{
Qualidade das águas do aquífero Barreiras no setor sul de Natal e norte de Parnamirim, Rio Grande do Norte, Brasil
}

\author{
Paula Stein $^{1 *}$, José Braz Diniz Filho ${ }^{2}$, Leandson Roberto Fernandes de Lucena ${ }^{3}$, \\ Natalina Maria Tinoco Cabral
}

\begin{abstract}
Resumo A cidade de Natal é abastecida em grande parte por águas do aquífero Barreiras e apesar da importância que tem as águas subterrâneas, a sua qualidade vem sendo comprometida pela ausência de sistema de esgotamento sanitário e seu tratamento adequado, que possibilite o descarte no solo. O presente estudo consiste na caracterização hidroquímica de um setor do aquífero Barreiras na região sul de Natal e norte de Parnamirim, mediante a amostragem de águas subterrâneas para análise físico-química em seis poços tubulares localizados no Centro de Lançamento da Barreira do Inferno e entorno. No setor investigado, as águas subterrâneas tendem a serem cloretadas sódicas com baixa salinidade (condutividade elétrica média de $71,7 \mu \mathrm{S} / \mathrm{cm}$ ). Os estudos apontam que as águas do aquífero Barreiras no trecho avaliado são passiveis de consumo sem prejuízo para a saúde humana de acordo com os padrões de potabilidade vigentes no Brasil. Apesar desse cenário favorável, foi evidenciado um poço (P5) localizado em área residencial em processo inicial de alteração da qualidade natural do aquífero pela contaminação de águas subterrâneas por efluentes domésticos. O referido poço apresenta valores elevados para alguns parâmetros (condutividade elétrica, sódio, nitrato e sulfato) quando comparados aos demais resultados analíticos obtidos no estudo. Ainda que se trate de um caso pontual e que os teores verificados não ultrapassem os limites de potabilidade, merece destaque para que sejam tomadas medidas de proteção das águas do aquífero Barreiras no trecho avaliado. A importância da área estudada do ponto de vista da qualidade das águas é extremamente relevante, uma vez que apresenta um dos poucos remanescentes florestais preservados na região, podendo ser considerada como um dos setores estratégicos para futura extração e atendimento da demanda urbana com água subterrânea.
\end{abstract}

Palavras-chave: hidrogeoquímica; aquífero Barreiras; qualidade da água.

Abstract The quality of Barreiras aquifer waters in south of Natal and north of Parnamirim, Rio Grande do Norte, Brazil. The city of Natal is supplied largely by the Barreiras aquifer waters in spite of the importance of groundwater, its quality is being compromised by the lack of sewerage systems and appropriate treatment to allow disposal in the soil. The present study is to characterize hydrochemistry of a sector of the Barreiras aquifer in Natal and the metropolitan area by the sampling of groundwater for physical-chemical analysis in six wells located in the Launch Center Barreira do Inferno and surroundings. In the area investigated, groundwater preserve its natural quality, tend to be sodium chlorinated with an average electrical conductivity of $71.7 \mu \mathrm{S} / \mathrm{cm}$. Studies indicate that the waters of the Barreiras aquifer are acceptable to consumption without harming human health according to the potability standards prevailing in Brazil. Despite this favorable scenario, there was evidence of a well (P5) located in a residential area in a initial process of change the natural quality of the aquifer by contamination of wastewater. This well has high values for some parameters (electrical conductivity, nitrate and sulfate) when compared to other analytical results obtained in the study. Although it is an isolated case and that the levels detected do not exceed the limits for drinking water, it deserves some attention to protect the water of Barreiras aquifer. The importance of the area in terms of water quality is extremely important, since it presents one of the few remaining preserved forest in the region and can be regarded as one of the strategic sectors for future extraction and meet the demand of urban groundwater.

Keywords: hydrogeochemistry; Barreiras aquifer; water quality.

\section{INTRODUÇÃO As águas subterrâneas re-} presentam a principal fonte de suprimento hídrico da cidade de Natal e região metropolitana. A distribuição dessa água é gerenciada pela Companhia de Águas e Esgotos do Rio Grande do Norte (CAERN), cuja demanda é atendida em $65 \%$ pela captação do aquífero Barreiras, e o restante provém de águas superficiais localizadas na periferia da cidade.

Apesar da importância que as águas subterrâneas representam para o abastecimento da cidade, a sua qualidade vem se demonstrando deteriorada em função da deficiência de sistema de esgotamento

${ }^{1}$ Secretaria de Estado do Meio Ambiente e dos Recursos Hídricos do Rio Grande do Norte - SEMARH, Natal (RN), Brasil. E-mail: paula.stein@gmail.com,natalinacabral@gmail.com

${ }^{2}$ Departamento de Geologia, Universidade Federal do Rio Grande do Norte - UFRN, Natal (RN), Brasil. E-mail: brazdf@geologia.ufrn.br ${ }^{3}$ Departamento de Geofísica, Universidade Federal do Rio Grande do Norte - UFRN, Natal (RN), Brasil. E-mail: leandson_lucena@ yahoo.com.br

*Autor correspondente 
sanitário e de tratamento que possibilite uma disposição final adequada dos efluentes domésticos. Em condições naturais, as águas do aquífero Barreiras são de excelente qualidade, muito embora áreas expressivas da cidade de Natal e entorno já estejam contaminadas por nitrato com teores acima de $10 \mathrm{mg} / \mathrm{L} \mathrm{N}$ (45 mg/ $\mathrm{L} \mathrm{NO}_{3}^{-}$) que é o padrão de potabilidade das águas de acordo com a Portaria $\mathrm{n}^{\circ} 2.914$ do Ministério da Saúde (MS) do Brasil (Brasil 2011).

Cabral (2007) fez um diagnóstico das águas subterrâneas de bairros da zona sul de Natal a partir dos dados químicos de águas de poços da CAERN do período de 1999 a 2006, e concluiu que os poços desse setor da cidade vêm apresentando um processo crescente de contaminação por nitrato no decorrer dos anos. A FUCERN (Rio Grande do Norte 2006) realizou o monitoramento da qualidade da água em 63 poços distribuídos na cidade de Natal durante o ano de 2006. De acordo com os resultados obtidos, as águas subterrâneas das zonas sul e norte da cidade apresentam teores médio de nitrato variando de menos de 1 até mais $45 \mathrm{mg} / \mathrm{L} \mathrm{N}$. Na zona sul de Natal, o setor sul de Ponta Negra que se estende até a Lagoa de Jiqui é um dos poucos domínios da cidade que ainda não se encontram contaminados.

A área de estudo (Fig. 1) está inserida na região sul da cidade de Natal (contemplando o bairro de Ponta Negra) e norte do município de Parnamirim (contemplando a localidade de Pium). Nesse setor está localizado o Centro de Lançamento da Barreira do Inferno (CLBI), pertencente ao Ministério da Defesa do Brasil. Trata-se de uma região preservada, com cerca de $15 \mathrm{~km}^{2}$, paralela à linha de costa e composta em superfície por materiais essencialmente arenosos dispostos na forma de campos dunares móveis e fixos. A sua importância ambiental é extremamente relevante, uma vez que se constitui num dos poucos remanescentes florestais protegidos na região metropolitana de Natal, caracterizando os campos dunares como uma área de recepção e transferência de água de chuva por drenança vertical descendente que recarrega naturalmente o aquífero Barreiras. O objetivo
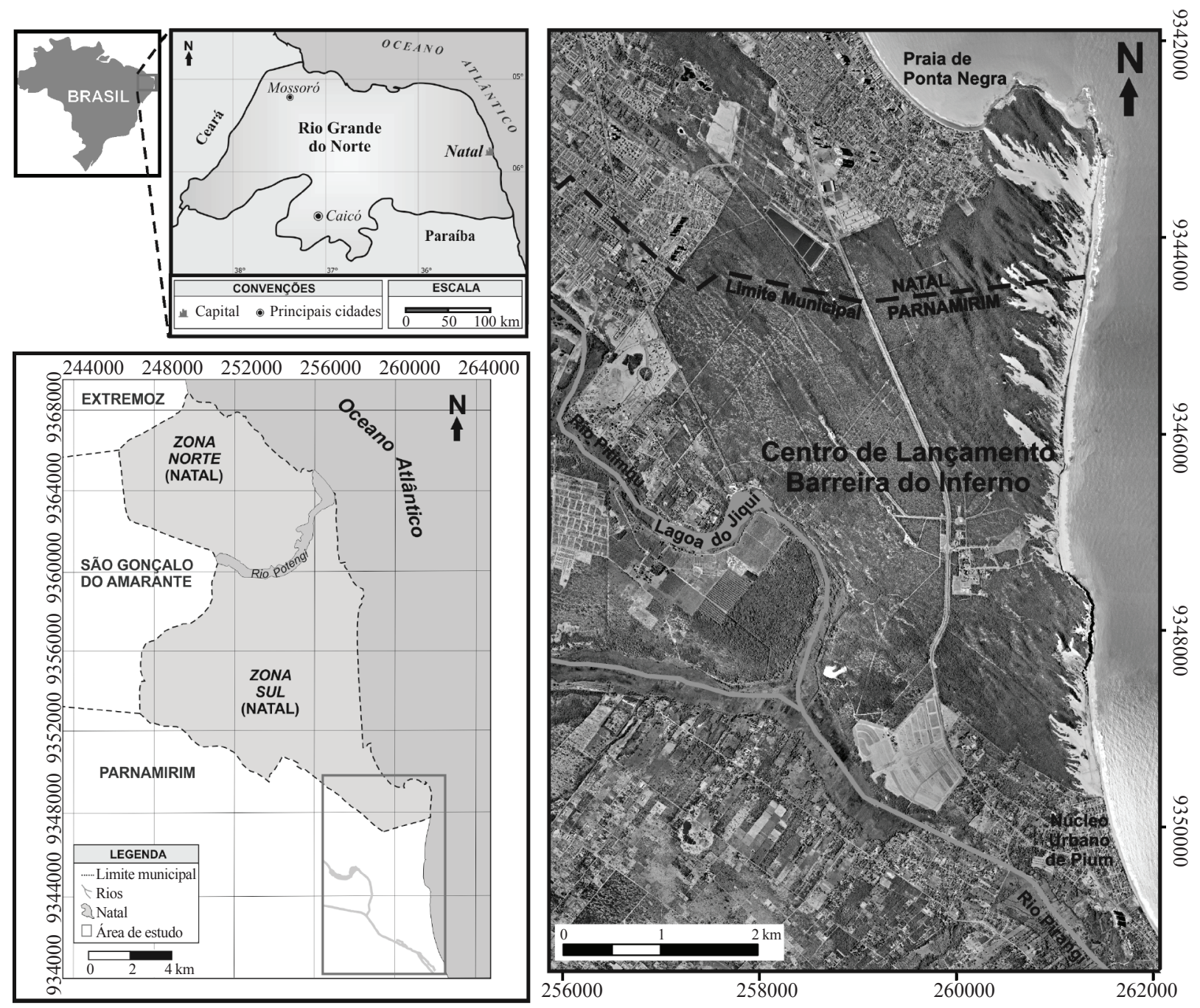

Figura 1 -Localização da área de estudo. 
desse trabalho foi caracterizar a área do ponto de vista hidrogeoquímico, demonstrando a qualidade das águas do aquífero Barreiras no trecho considerado.

GEOLOGIA A área de estudo está inserida na Bacia Sedimentar Costeira Leste do Estado do RN (Fig. 2). A referida bacia ocorre regionalmente numa faixa com largura média aproximada de $30 \mathrm{~km}$ (na direção leste-oeste), entre o oceano Atlântico ao leste e o início do embasamento aflorante, a oeste. A geometria e dimensões da bacia costeira são determinadas pelo arcabouço estrutural desenvolvido no embasamento.

São individualizadas as seguintes unidades:

- Sequência sedimentar siliciclástica de idade quaternária no topo: compreende os sedimentos siliciclásticos eólicos essencialmente areno-quartzosos que formam as dunas fixas e móveis, ocorrendo com mais frequência nas faixas próximas à linha de costa, sobrejacentes às rochas da Formação Barreiras. Inclui também sedimentos fluviais formados por processos de deposição fluvial nos canais e margens dos rios que deságuam no mar, cuja foz permite desenvolver a sedimentação de mangues por influência direta das marés.

- Rochas sedimentares siliciclásticas de idade terciária-quaternária: compreende principalmente as rochas siliciclásticas continentais pouco consolidadas, de caráter areno-argiloso a argiloso (arenitos argilosos, argilitos arenosos, siltitos, conglomerados etc.) que compõem a Formação Barreiras. Na área de estudo estão sobrejacentes diretamente às rochas carbonáticas Cretáceas.

- Rochas carbonáticas cretáceas na base: unidade litoestratigráfica carbonática não aflorante, sobreposta diretamente ao embasamento cristalino e subjacente ao material sedimentar tércio-quaternário. Compõe-se por rochas calcárias areno-argilosas a argilosas e arenitos calcíferos.

Localmente a área de estudo é constituída por sedimentos e rochas siliciclásticas de idade tércio-quaternária da Formação Barreiras e coberturas recentes de dunas.

A espessura da Formação Barreiras varia de 50 a $120 \mathrm{~m}$. A porção superior dos perfis é predominantemente argilosa, composta por arenitos argilosos, argilas arenosas, siltitos, argilas e intercalações de arenitos de granulação fina a grossa com coloração geralmente avermelhada. Na porção inferior da Formação Barreiras predominam arenitos de granulação fina a grossa, com intercalações argilosas. Apresentam coloração predominantemente clara (creme a amarelada) e localmente ocorrem níveis de seixos arredondados a subarredondados.

As dunas têm espessura média de $10 \mathrm{~m}$ e são compostas por areias quartzosas finas a médias, homogêneas, bem selecionadas e de coloração esbranquiçada.

HIDROGEOLOGIA Diante do contexto geológico, o padrão hidroestratigráfico e hidrogeológico da região costeira leste do Estado do Rio Grande do

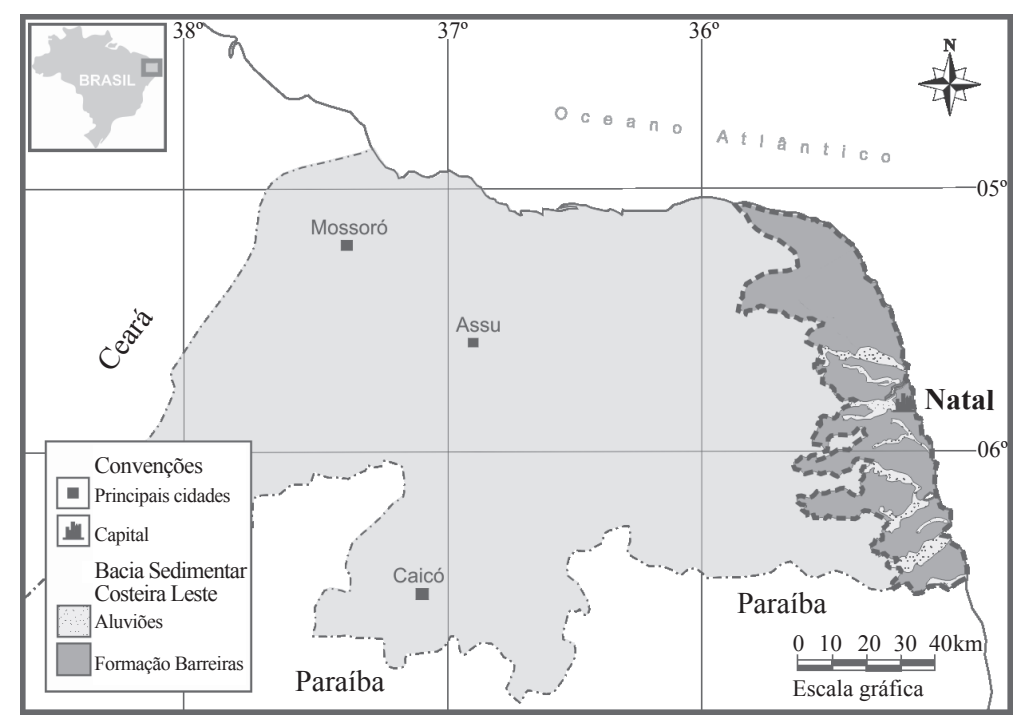

Figura 2 - Geologia simplificada da Bacia Sedimentar Costeira Leste do estado do Rio Grande do Norte. 
Norte é representado pelo aquífero Barreiras de caráter poroso granular e localizado preferencialmente na porção inferior da formação homônima. No tocante à condição hidrodinâmica, o aquífero Barreiras comporta-se de maneira bastante variável, sobretudo na região sul de Natal até a fronteira com a Paraíba. O referido aquífero pode apresentar-se de livre a semiconfinado, onde a camada semiconfinante, quando presente, é representada por horizontes ou lentes argilosas da própria Formação Barreiras (IPT 1982).

As sequências de sedimentos eólicos (dunas fixas e móveis) sobrejacentes ao aquífero Barreiras ocorrem nos setores mais próximos à linha de costa e constituem preferencialmente numa unidade de transferência de águas de chuva, que favorecem a recarga do aquífero Barreiras subjacente por meio de drenança vertical descendente. Dessa forma, o compartimento das dunas apresenta-se predominantemente insaturado e não representam uma unidade aquífera de explotação e produção de água para abastecimento (Diniz Filho, Lucena, Stein 2009).
O aquífero Barreiras é responsável pelo abastecimento da maioria das cidades da faixa litorânea oriental do Rio Grande do Norte. Sua constituição litológica é bastante diversificada em termos de granulometria, envolvendo desde argilitos a arenitos conglomeráticos, com predomínio de arenitos argilosos de matriz argilo-siltosa. O limite inferior do referido aquífero é o topo da sequência carbonática mesozóica não aflorante na região, a qual é constatada apenas em perfurações de poços e referidas na literatura como de baixa potencialidade hidrogeológica (Lucena \& Queiroz 1996, Lucena et al. 2004). O limite inferior do aquífero Barreiras já nas proximidades do limite ocidental da bacia sedimentar costeira é representado pelo próprio embasamento cristalino.

MATERIAIS E MÉTODOS A amostragem envolveu a coleta de águas subterrâneas em seis poços tubulares localizados no Centro de Lançamentos da Barreira do Inferno e adjacências. Na Fig. 3 pode-se visualizar a distribuição espacial dos poços
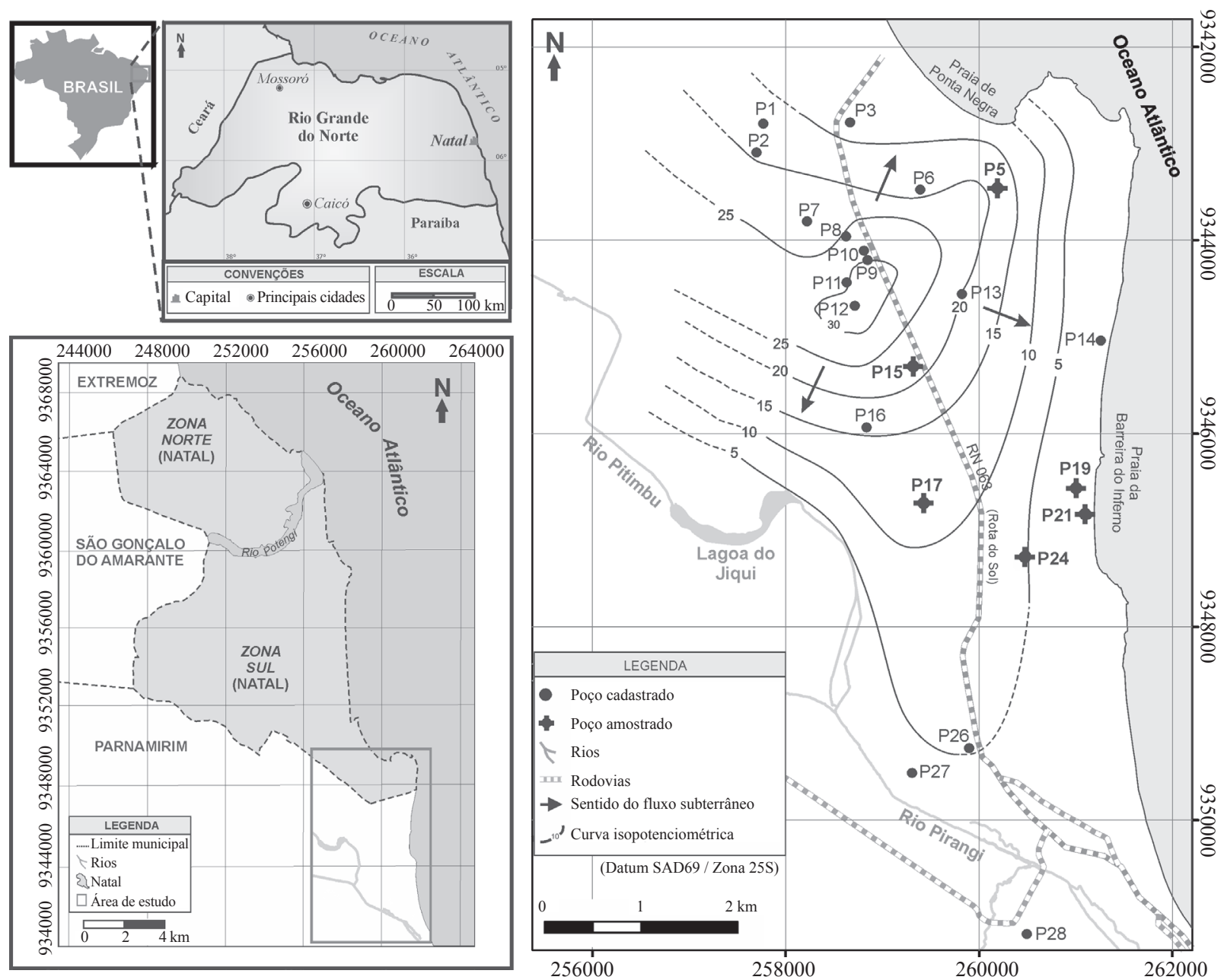

Figura 3 - Fluxo das águas subterrâneas na área de estudo e localização dos poços amostrados (Diniz Filho, Lucena, Stein 2009). 
amostrados e dos poços cadastrados no âmbito da área. O critério de seleção dos poços amostrados considerou o acesso às amostras diretamente da boca do poço, isto é, antes do armazenamento em reservatórios ou a passagem da água por tubulação de superfície.

Na Tab. 1 são apresentados os dados construtivos e hidráulicos dos poços cadastrados, os quais foram utilizados na confecção do mapa potenciométrico apresentado na Fig. 3, elaborado para o mês de abril de 2009. Na referida figura observa-se um divisor de águas subterrâneas com direção geral NW-SE, representado no mapa por um alto potenciométrico entre as cotas 25 a $30 \mathrm{~m}$, a partir daí o fluxo das águas subterrâneas se desenvolve segundo três frentes de escoamento preferenciais, as quais: (1) sentido norte/nordeste em direção a Praia de Ponta Negra; (2) sentido leste em direção a Praia da Barreira do Inferno; (3) sentido sul/sudoeste em direção ao Rio Pitimbu (Lagoa do Jiqui).

A amostragem ocorreu entre 13 e 23 de abril de 2009. Para a coleta foi realizada uma prévia purga nos poços por aproximadamente 30 minutos, com vistas à obtenção de dados representativos do manancial subterrâneo, minimizando as chances de serem coletadas águas estagnadas no interior da captação.

As amostras foram acondicionadas em recipientes de polietileno esterilizado e lavados em campo com a própria água a ser coletada. Posteriormente foram preservadas em caixa térmica com gelo e enviadas ao laboratório da Empresa de Pesquisa Agropecuária do Rio Grande do Norte (EMPARN) no mesmo dia, para que o início da análise fosse realizado no máximo um dia após a coleta.

Na Tab. 2 são sumarizados os parâmetros analisados no âmbito desse estudo, as técnicas laboratoriais utilizadas na sua determinação e o limite de detecção informado pelo laboratório. O dióxido de carbono $\left(\mathrm{CO}_{2}\right)$ livre foi calculado a partir dos valores de $\mathrm{pH}$ e dos teores de bicarbonato, conforme Custódio e Llamas (1983). Os procedimentos de coleta, armazenamento e análise basearam-se nos métodos padrões propostos pela American Public Health Association (APHA 2005). A qualidade analítica dos dados foi verificada através do cálculo do erro da análise, baseado no balanço iônico. Posteriormente, os dados foram tratados e interpretados com o auxílio do software Excel para Windows e AcquaChem - Aqueous Geochemical Analisys, Plotting and Modeling. Na Tab. 3 são

Tabela 1 - Parâmetros construtivos e hidráulicos dos poços cadastrados

\begin{tabular}{|c|c|c|c|c|c|c|c|c|c|c|}
\hline Ponto & Tipo & Proprietário & $\begin{array}{c}\text { Leste } \\
\text { (UTM, m) }\end{array}$ & $\begin{array}{c}\text { Norte } \\
\text { (UTM, m) }\end{array}$ & $\begin{array}{l}\text { Prof. } \\
\text { (m) }\end{array}$ & Diâm. & Uso atual & $\begin{array}{c}\text { Cota } \\
\text { Topográfica } \\
(\mathrm{m})\end{array}$ & $\begin{array}{c}\text { Nível } \\
\text { Estático } \\
(\mathrm{m})\end{array}$ & $\begin{array}{c}\text { Cota } \\
\text { Potenciométrica } \\
(\mathrm{m})\end{array}$ \\
\hline$\overline{\mathrm{P} 1}$ & $\mathrm{Pz}$ & Particular & 257761,76 & 9349198,35 & 51 & $4 "$ & Captação & 35,8 & 18,61 & 17,19 \\
\hline $\mathrm{P} 2$ & Poço & Particular & 257696,21 & 9348908,99 & 80 & $8 "$ & Captação & 38,68 & 20,52 & 18,16 \\
\hline P3 & Poço & CAERN & 258665,00 & 9349220,00 & 88 & $6 "$ & Captação & 35,76 & 23,71 & 12,05 \\
\hline $\mathrm{P} 5$ & Poço & CAERN & 260191,41 & 9348538,50 & 101 & $6 "$ & Captação & 32,48 & 12,61 & 19,87 \\
\hline P6 & Poço & CAERN & 259382,00 & 9348522,00 & 105 & $6 "$ & Captação & 42,43 & 23,7 & 18,73 \\
\hline P7 & $\mathrm{Pz}$ & CAERN & 258220,46 & 9348195,15 & 90 & $6 "$ & Monitoramento & 39,63 & 18,69 & 20,94 \\
\hline$\overline{\mathrm{P} 8}$ & $\mathrm{Pz}$ & CAERN & 258626,00 & 9348060,00 & 50 & $2 "$ & Monitoramento & 36,83 & 12,03 & 24,80 \\
\hline P9 & $\mathrm{Pz}$ & CAERN & 258827,00 & 9347851,00 & 50 & $2 "$ & Monitoramento & 33,41 & 3,56 & 29,85 \\
\hline $\mathrm{P} 10$ & $\mathrm{Pz}$ & CAERN & 258818,00 & 9347862,00 & 110 & $2 "$ & Monitoramento & 33,34 & 6,22 & 27,12 \\
\hline P11 & $\mathrm{Pz}$ & CAERN & 258630,00 & 9347565,00 & 50 & 4" & Monitoramento & 29,48 & 3,32 & 26,16 \\
\hline P12 & $\mathrm{Pz}$ & CAERN & 258715,00 & 9347322,00 & 50 & $2 "$ & Monitoramento & 35,27 & 4,8 & 30,47 \\
\hline P13 & $\mathrm{Pz}$ & CLBI/CAERN & 259813,07 & 9347435,11 & 19 & $2 "$ & Pesquisa & 38,90 & 15,19 & 23,71 \\
\hline P14 & $\mathrm{Pz}$ & CLBI/CAERN & 261259,53 & 9346964,26 & 17 & $2 "$ & Pesquisa & 12,89 & 9,73 & 3,16 \\
\hline P15 & Poço & CAERN & 259394,86 & 9346741,48 & 100 & $8 "$ & Pesquisa & 35,59 & 14,6 & 20,99 \\
\hline P16 & Poço & CLBI & 258837,81 & 9346063,60 & 69 & $6 "$ & Captação & 41,84 & 26,36 & 15,48 \\
\hline P17 & Poço & CLBI & 259428,02 & 9345283,50 & 110 & $6 "$ & Captação & 43,11 & 31 & 12,11 \\
\hline P19 & $\mathrm{Pz}$ & CLBI/CAERN & 261129,74 & 9345155,32 & 50 & $4 "$ & Pesquisa & 9,91 & 5,91 & 3,99 \\
\hline P21 & Poço & CLBI/CAERN & 261133,91 & 9345146,45 & 75 & $6 "$ & Pesquisa & 9,72 & 5,41 & 4,31 \\
\hline $\mathrm{P} 24$ & Poço & CLBI & 260397,09 & 9344648,54 & 70 & $6 "$ & Captação & 40,24 & 27,47 & 12,77 \\
\hline $\mathrm{P} 26$ & Poço & Particular & 259898,27 & 9342746,32 & 110 & $8 "$ & Captação & 41,94 & 33 & 8,94 \\
\hline $\mathrm{P} 27$ & Poço & Particular & 259307,36 & 9342488,53 & 102 & $8 "$ & Captação & 24,60 & 20,04 & 4,56 \\
\hline P28 & Poço & CAERN & 260495,91 & 9340820,72 & 67 & $6 "$ & Captação & 24,06 & 19,1 & 4,96 \\
\hline
\end{tabular}

Pz: Piezômetro; CLBI: Centro de Lançamento da Barreira do Inferno; CAERN: Companhia de Águas e Esgotos do Rio Grande do Norte; Prof.: Profundidade; Diâm.: Diâmetro 
Tabela 2 - Parâmetros determinados, técnica analítica e limite de detecção do método utilizado

\begin{tabular}{|c|c|c|c|}
\hline Determinação & Unidade & Técnica Analítica & LD \\
\hline Temperatura & ${ }^{\circ} \mathrm{C}$ & Leitura Direta - Termômetro de Hg & - \\
\hline Cor & $\mathrm{uH}$ & Comparação Visual - Padrões de Platina -Cobalto & - \\
\hline Turbidez & UT & Comparação Visual - Padrões de Sílica & - \\
\hline $\mathrm{pH}$ & Adimensional & Potenciométrico & - \\
\hline Condutividade elétrica & $\mu \mathrm{S} / \mathrm{cm}$ & Calculado a partir do SDT & - \\
\hline Sólidos totais a $105^{\circ} \mathrm{C}$ & $\mathrm{mg} / \mathrm{L}$ & Gravimétrico & - \\
\hline Sólidos dissolvidos totais & $\mathrm{mg} / \mathrm{L}$ & Gravimétrico & 0,1 \\
\hline Sólidos em suspensão & $\mathrm{mg} / \mathrm{L}$ & Gravimétrico & - \\
\hline Alcalinidade total & $\mathrm{mg} / \mathrm{L} \mathrm{CaCO}_{3}$ & Titulação potenciométrica & 1,0 \\
\hline Alcalinidade de bicarbonato & $\mathrm{mg} / \mathrm{L} \mathrm{CaCO}_{3}$ & Titulação potenciométrica & - \\
\hline Dureza total & $\mathrm{mg} / \mathrm{L} \mathrm{CaCO}_{3}$ & Volumétrico - EDTA & - \\
\hline Nitrogênio amoniacal & $\mathrm{mg} / \mathrm{L} \mathrm{NH}_{3}$ & Colorimétrico - Nessler & 0,02 \\
\hline Nitrito & $\mathrm{mg} / \mathrm{L} \mathrm{N}$ & Colorimétrico - N(1-naftil) Etilenodiamina & 0,01 \\
\hline Nitrato & $\mathrm{mg} / \mathrm{L} \mathrm{N}$ & Colorimétrico - Redução coluna de cádmio cobreado & 0,04 \\
\hline Cálcio & $\mathrm{mg} / \mathrm{L} \mathrm{Ca}^{2+}$ & Volumétrico - EDTA & 0,1 \\
\hline Magnésio & $\mathrm{mg} / \mathrm{L} \mathrm{Mg}^{2+}$ & Volumétrico - EDTA & 0,1 \\
\hline Sódio & $\mathrm{mg} / \mathrm{L} \mathrm{Na}^{+}$ & Fotometria de chama & 0,1 \\
\hline Potássio & $\mathrm{mg} / \mathrm{L} \mathrm{K}^{+}$ & Fotometria de chama & 0,1 \\
\hline Ferro & $\mathrm{mg} / \mathrm{L} \mathrm{Fe}$ & Colorimétrico - fenantrolina & 0,1 \\
\hline Bicarbonato & $\mathrm{mg} / \mathrm{L} \mathrm{HCO}_{3}^{-}$ & Calculado a partir da alcalinidade & - \\
\hline Sulfato & $\mathrm{mg} / \mathrm{L} \mathrm{SO}_{4}^{2-}$ & Turbidimétrico & 1 \\
\hline Cloreto & $\mathrm{mg} / \mathrm{L} \mathrm{Cl}^{-}$ & Volumétrico - Nitrato de Prata & 1,5 \\
\hline
\end{tabular}

LD: limite de detecção; SDT: sólidos dissolvidos totais

Tabela 3 - Resultados analíticos das águas amostradas no aquífero Barreiras nas imediações do Centro de Lançamento da Barreira do Inferno e valor máximo permitido estabelecido pela Portaria $n^{\circ} 2.914$ do Ministério da Saúde do Brasil

\begin{tabular}{|c|c|c|c|c|c|c|c|c|}
\hline \multirow{2}{*}{ Determinação } & \multirow{2}{*}{ Unidade } & \multirow{2}{*}{ VMP* } & \multicolumn{6}{|c|}{ Resultado Analítico } \\
\hline & & & P5 & P15 & P21 & P24 & P17 & P19 \\
\hline Temperatura & ${ }^{\circ} \mathrm{C}$ & & 25 & 25 & 25 & 25 & 25 & 25 \\
\hline Cor & $\mathrm{uH}$ & 15 & 2,5 & 10 & 2,5 & 5 & 2,5 & 7,5 \\
\hline Turbidez & UT & & 0,40 & 15 & 1 & 3,83 & 0,40 & 0,65 \\
\hline $\mathrm{pH}$ & Adimensional & & 5,60 & 6,80 & 7,10 & 6,40 & 4,30 & 6,90 \\
\hline Condutividade elétrica & $\mu \mathrm{S} / \mathrm{cm}$ & & 113,00 & 69,30 & 65,90 & 45,90 & 50,00 & 86,10 \\
\hline Sólidos totais a $105^{\circ} \mathrm{C}$ & $\mathrm{mg} / \mathrm{L}$ & & 76,80 & 56,00 & 44,81 & 31,20 & 34,00 & 58,55 \\
\hline Sólidos dissolvidos totais & $\mathrm{mg} / \mathrm{L}$ & 1.000 & 76,80 & 47,12 & 44,81 & 31,20 & 34,00 & 58,55 \\
\hline Sólidos em suspensão & $\mathrm{mg} / \mathrm{L}$ & & $<\mathrm{LD}$ & 8,88 & $<\mathrm{LD}$ & $<\mathrm{LD}$ & $<\mathrm{LD}$ & $<\mathrm{LD}$ \\
\hline Alcalinidade total & $\mathrm{mg} / \mathrm{L} \mathrm{CaCO}_{3}$ & & 2,02 & 21,26 & 17,21 & 5,06 & $<\mathrm{LD}$ & 12,15 \\
\hline Alcalinidade de bicarbonato & $\mathrm{mg} / \mathrm{L} \mathrm{CaCO}_{3}$ & & 2,02 & 21,26 & 17,21 & 5,06 & $<\mathrm{LD}$ & 12,15 \\
\hline Dureza total & $\mathrm{mg} / \mathrm{L}$ como $\mathrm{CaCO}_{3}$ & 500 & 14,63 & 28,29 & 19,51 & 9,76 & 7,80 & 18,53 \\
\hline Nitrogênio amoniacal & $\mathrm{mg} / \mathrm{L} \mathrm{NH}_{3}$ & & 0,12 & 0,13 & 0,15 & 0,29 & 0,16 & 0,02 \\
\hline Nitrito & $\mathrm{mg} / \mathrm{L} \mathrm{N}$ & 1 & $<\mathrm{LD}$ & $<\mathrm{LD}$ & $<\mathrm{LD}$ & $<\mathrm{LD}$ & $<\mathrm{LD}$ & $<\mathrm{LD}$ \\
\hline Nitrato & $\mathrm{mg} / \mathrm{L} \mathrm{N}$ & 10 & 4,15 & 0,23 & 0,17 & 1,08 & 0,16 & 0,2 \\
\hline Cálcio & $\mathrm{mg} / \mathrm{L} \mathrm{Ca}^{2+}$ & & 2,34 & 8,98 & 3,91 & 2,73 & 1,56 & 5,47 \\
\hline Magnésio & $\mathrm{mg} / \mathrm{L} \mathrm{Mg}^{2+}$ & & 2,13 & 1,42 & 2,37 & 0,71 & 0,95 & 1,18 \\
\hline Sódio & $\mathrm{mg} / \mathrm{L} \mathrm{Na}^{+}$ & 200 & 22,00 & 7,83 & 6,09 & 8,69 & 10,44 & 12,80 \\
\hline Potássio & $\mathrm{mg} / \mathrm{L} \mathrm{K}^{+}$ & & 1,30 & 0,43 & 4,78 & $<\mathrm{LD}$ & 0,43 & 1,20 \\
\hline Ferro & $\mathrm{mg} / \mathrm{L} \mathrm{Fe}$ & 0,30 & 0,03 & 0,28 & 0,09 & 0,17 & 0,27 & 0,05 \\
\hline Bicarbonato & $\mathrm{mg} / \mathrm{L} \mathrm{HCO}_{3}^{-}$ & & 3,25 & 22,49 & 18,44 & 6,18 & $<\mathrm{LD}$ & 14,82 \\
\hline Sulfato & $\mathrm{mg} / \mathrm{L} \mathrm{SO}_{4}^{2-}$ & 250 & 17,60 & $<\mathrm{LD}$ & $<\mathrm{LD}$ & 9,51 & 13,29 & 1,82 \\
\hline Cloreto & $\mathrm{mg} / \mathrm{L} \mathrm{Cl}^{-}$ & 250 & 19,88 & 16,57 & 16,57 & 9,94 & 16,57 & 23,19 \\
\hline $\mathrm{CO}_{2}$ livre & $\mathrm{mg} / \mathrm{L}$ & & 5,56 & 34,94 & 28,2 & 9,42 & 1,7 & 22,64 \\
\hline
\end{tabular}

VMP: valor máximo permitido pela Portaria nº 2.914 do Ministério da Saúde do Brasil, que estabelece padrões de potabilidade das águas para consumo humano; LD: limite de detecção 
apresentados os resultados analíticos obtidos e o valor máximo permitido para águas destinadas ao consumo humano, de acordo com a Portaria $\mathrm{n}^{\circ} 2.914$ do MS do Brasil (Brasil 2011).

Qualidade análitica dos dados $\mathrm{O}$ controle de qualidade dos resultados analíticos foi levado a efeito mediante o cálculo do erro da análise, baseado no balanço iônico, o qual determina que a concentração total dos íons positivos (cátions) (meq) deve ser aproximadamente igual à concentração total dos íons negativos (ânions) (meq).

A equação do balanço é definida como:

Erro da reação $(\%)=[100 \mathrm{~S}$ cátions (meq) $-\mathrm{S}$ anions (meq) $]$ / [S cátions (meq) $+\mathrm{S}$ anions (meq) $]$

Onde,

Cátions $=\mathrm{NH}_{4}, \mathrm{Ca}^{2+}, \mathrm{Mg}^{2+}, \mathrm{Na}^{+}, \mathrm{K}^{+}, \mathrm{Fe}$

Tabela 4 - Condutividade elétrica e erro máximo permitido no balanço iônico (Custódio \& Llamas 1983)

\begin{tabular}{lc}
\hline Condutividade elétrica $(\mathrm{mS} / \mathrm{cm})$ & Erro permitido $(\%)$ \\
\hline 50 & 30 \\
\hline 200 & 10 \\
\hline 500 & 8 \\
\hline 2000 & 4 \\
\hline$>2.000$ & $<4$ \\
\hline
\end{tabular}

Tabela 5 - Condutividade elétrica das águas e erro da análise baseado no balanço iônico

\begin{tabular}{lcccccc}
\hline Poço & P5 & P15 & P21 & P24 & P17 & P19 \\
\hline CE $(\mu \mathrm{S} / \mathrm{cm})$ & 113,00 & 69,30 & 65,90 & 45,90 & 50,00 & 86,10 \\
\hline Erro $(\%)$ & 7,15 & 7,87 & 0,56 & 1,81 & 3,94 & 0,64 \\
\hline
\end{tabular}

Ânions $=\mathrm{NO}_{2}^{-}, \mathrm{NO}_{3}^{-}, \mathrm{HCO}_{3}^{-}, \mathrm{CO}_{3}, \mathrm{SO}_{4}^{2-}, \mathrm{Cl}^{-}$

O princípio deste método está baseado na neutralidade da água, ou seja, na carga total nula. O balanço iônico consiste em calcular a razão da diferença entre as somatórias das concentrações iônicas de ânions e cátions (expressas em meq/L). Custódio e Llamas (1983) explicam que essa diferença é devida à acumulação de erros na determinação de cada variável e por desprezar as contribuições iônicas menores.

Para Custódio e Llamas (1983), o erro admissível depende da concentração iônica e do tipo de água, portanto, é proporcional à condutividade elétrica das águas conforme Tab. 4.

A condutividade elétrica das águas do aquífero Barreiras na região de estudo apresentou valores entre 45,90 e $113,00 \mu \mathrm{S} / \mathrm{cm}$; e o erro da análise variou de 0,56 a $7,87 \%$, conforme Tab. 5. Comparando os percentuais de erros obtidos nas análises com a respectiva condutividade elétrica da água amostrada, pode-se admitir que os dados utilizados no presente trabalho são confiáveis segundo o critério do balanço iônico.

\section{HIDROGEOQUÍMICA DO AQUÍFERO}

BARREIRAS A estatística descritiva foi aplicada às 20 variáveis estudadas, com o objetivo de facilitar a interpretação dos dados hidroquímicos obtidos. Foram calculados média, mediana, desvio padrão, mínimo e máximo conforme mostrado na Tab. 6. Todos os parâmetros avaliados apresentaram concentração inferior ao valor máximo permitido (VMP) determinado pelos padrões de

Tabela 6-Estatística descritiva da composição química das águas do aquifero Barreiras no setor analisado ( $n=6$ )

\begin{tabular}{llccccc}
\hline Parâmetro & \multicolumn{1}{c}{ Unidade } & Média & Mediana & Desvio padrão & Mínimo & Máximo \\
\hline $\mathrm{pH}$ & Adimensional & 6,18 & 6,60 & 1,06 & 4,30 & 7,10 \\
\hline Condutividade elétrica & $\mu \mathrm{S} / \mathrm{cm}$ & 71,70 & 67,60 & 24,86 & 45,90 & 113,00 \\
\hline Sólidos totais a $105^{\circ} \mathrm{C}$ & $\mathrm{mg} / \mathrm{L}$ & 50,23 & 50,41 & 17,11 & 31,20 & 76,80 \\
\hline Sólidos dissolvidos totais & $\mathrm{mg} / \mathrm{L}$ & 48,75 & 45,97 & 16,89 & 31,20 & 76,80 \\
\hline Alcalinidade total & $\mathrm{mg} / \mathrm{L} \mathrm{CaCO}_{3}$ & 9,78 & 8,61 & 8,39 & 1,00 & 21,26 \\
\hline Alcalinidade de bicarbonato & $\mathrm{mg} / \mathrm{L} \mathrm{CaCO}_{3}$ & 9,78 & 8,61 & 8,39 & 1,00 & 21,26 \\
\hline Dureza total & $\mathrm{mg} / \mathrm{L} \mathrm{como}^{-} \mathrm{CaCO}_{3}$ & 16,42 & 16,58 & 7,44 & 7,80 & 28,29 \\
\hline Nitrogênio amoniacal & $\mathrm{mg} / \mathrm{L} \mathrm{NH}_{3}$ & 0,15 & 0,14 & 0,09 & 0,02 & 0,29 \\
\hline Nitrato & $\mathrm{mg} / \mathrm{L} \mathrm{N}^{2+}$ & 1,00 & 0,22 & 1,58 & 0,16 & 4,15 \\
\hline Cálcio & $\mathrm{mg} / \mathrm{L} \mathrm{Ca}^{2+}$ & 4,17 & 3,32 & 2,73 & 1,56 & 8,98 \\
\hline Magnésio & $\mathrm{mg} / \mathrm{L} \mathrm{Mg}^{2+}$ & 1,46 & 1,30 & 0,66 & 0,71 & 2,37 \\
\hline Sódio & $\mathrm{mg} / \mathrm{L} \mathrm{Na}^{+}$ & 11,31 & 9,57 & 5,72 & 6,09 & 22,00 \\
\hline Potássio & $\mathrm{mg} / \mathrm{L} \mathrm{K}^{+}$ & 1,37 & 0,82 & 1,73 & 0,10 & 4,78 \\
\hline Ferro & $\mathrm{mg} / \mathrm{L} \mathrm{Fe}^{-}$ & 0,15 & 0,13 & 0,11 & 0,03 & 0,28 \\
\hline Bicarbonato & $\mathrm{mg} / \mathrm{L} \mathrm{HCO}_{3}^{-}$ & 11,03 & 10,50 & 8,78 & 1,00 & 22,49 \\
\hline Sulfato & $\mathrm{mg} / \mathrm{L} \mathrm{SO}_{4}^{2-}$ & 7,37 & 5,67 & 7,16 & 1,00 & 17,60 \\
\hline Cloreto & $\mathrm{mg} / \mathrm{L} \mathrm{Cl}^{-}$ & 17,12 & 16,57 & 4,40 & 9,94 & 23,19 \\
\hline
\end{tabular}


potabilidade brasileiros. A seguir são discutidos os principais resultados.

$\mathrm{O} \mathrm{pH}$ é a medida da concentração de íons $\mathrm{H}^{+}$ na água. $\mathrm{O}$ balanço dos íons hidrogênio e hidróxido $\left(\mathrm{OH}^{-}\right)$determinam se a água é ácida ou básica. Os principais fatores que determinam o $\mathrm{pH}$ da água são o $\mathrm{CO}_{2}$ dissolvido e a alcalinidade. Com base nos valores de $\mathrm{pH}$ das águas amostradas pode-se afirmar que as águas do aquífero Barreiras tendem a serem pouco ácidas com pH médio de 6,18.

Como há uma relação de proporcionalidade entre o teor de sais dissolvidos e a condutividade elétrica, pode-se estimar o teor de sais pela medida de condutividade de uma água. O valor médio da condutividade elétrica das águas analisadas é $71,70 \mu \mathrm{S} / \mathrm{cm}$, variando de 45,90 a $113,00 \mu \mathrm{S} / \mathrm{cm}$. Esses resultados evidenciam que as águas do aquífero Barreiras em condições naturais são pouco mineralizadas, isto é, apresentam baixa salinidade. Valores elevados de condutividade elétrica no aquífero Barreiras têm sido reportados na literatura à contaminação das águas, notadamente associados ao íon nitrato (Cabral 2007).

Os sólidos dissolvidos totais representam a soma dos teores de todos os constituintes minerais presentes na água. $\mathrm{O}$ valor médio obtido das análises é da ordem de $48,75 \mathrm{mg} / \mathrm{L}$, sendo classificadas como águas doces, de acordo com a Tab. 7.

A alcalinidade é a medida total das substâncias presentes na água capazes de neutralizarem ácidos. Em águas subterrâneas, a alcalinidade é devida principalmente aos carbonatos e bicarbonatos e, secundariamente, aos íons hidróxidos, silicatos, boratos, fosfatos e amônia (Hem 1985). No caso das águas do aquífero Barreiras, a alcalinidade é devida ao bicarbonato presente. $\mathrm{O}$ valor médio obtido é de 9,78 g/ $/ \mathrm{LaCO}_{3}$, variando de 1,00 a 21,26 mg/ $/ \mathrm{CaCO}_{3}$.

A dureza total é a soma da dureza temporária e a permanente. $\mathrm{O}$ íon cálcio é o principal elemento responsável pela dureza da água, seguido do magnésio. Para as águas amostradas no aquífero Barreiras, a média da dureza total é de $16,42 \mathrm{mg} / \mathrm{L}$ como $\mathrm{CaCO}_{3}$,

Tabela 7 - Classificação das águas conforme os sólidos totais dissolvidos (Mcneely, Neimanis, Dwyer 1979)

\begin{tabular}{lc}
\hline Tipo & STD $(\mathrm{mg} / \mathrm{L})$ \\
\hline Doces & $<1.000$ \\
\hline Ligeiramente salobras & $1.000-3.000$ \\
\hline Moderadamente salobras & $3.000-10.000$ \\
\hline Salgadas & $10.000-100.000$ \\
\hline Salmouras & $>100.000$ \\
\hline
\end{tabular}

sendo, portanto, classificada como águas brandas, conforme classificação da Tab. 8.

Os teores de nitrogênio amoniacal e nitrito nas águas analisadas apresentaram-se baixos, pois essas espécies nitrogenadas são rapidamente convertidas para nitrato pelas bactérias especializadas. Quando presente, o nitrogênio amoniacal pode indicar poluição recente relacionada à disposição de efluentes domésticos.

No caso do nitrito, todas as amostras apresentaram resultados analíticos inferiores ao limite de detecção (Tab. 3). Os teores de nitrogênio amoniacal variaram de 0,02 a 0,29 , com média de $0,15 \mathrm{mg} / \mathrm{L} \mathrm{NH}_{3}$.

Os valores de nitrato variaram entre $0,16 \mathrm{e}$ 4,15 mg/L de N com média de 1,00 mg/L de N. O teor mais elevados de nitrato foi verificado no poço P5 (4,15 mg/L de N) (Tab. 3) que está localizado numa área adensada da cidade. Trata-se de um poço de produção da CAERN, cujas águas podem ser consumidas pelo homem sem prejuízo para a sua saúde, de acordo com os padrões de potabilidade estabelecidos pelo MS do Brasil (Portaria ${ }^{\circ}$ 2.914) (Brasil 2011), que determina em $10 \mathrm{mg} / \mathrm{L}$ de $\mathrm{N}$ o valor máximo permitido. Porém, a presença desse teor nas águas deve servir de alerta, pois evidenciam o processo inicial de alteração da qualidade natural do aquífero por espécies nitrogenadas, provenientes de sistema sépticos e/ou de práticas inadequadas de saneamento. O nitrato é uma espécie química persistente, móvel e que não degrada facilmente em meio aeróbico subterrâneo, podendo migrar por grandes distâncias acompanhando o fluxo subterrâneo.

$\mathrm{O}$ cálcio ocorre nas águas na forma de bicarbonato e sua solubilidade é função da quantidade de $\mathrm{CO}_{2}$ dissolvido. A quantidade de $\mathrm{CO}_{2}$ dissolvido depende da temperatura e da pressão, que são, portanto, fatores que determinarão a solubilidade ou precipitação do bicarbonato de cálcio. $\mathrm{O}$ teor de cálcio nas águas subterrâneas estudadas variou de 1,56 a $8,98 \mathrm{mg} / \mathrm{L}$, com média de $4,17 \mathrm{mg} / \mathrm{L}$.

O magnésio é um elemento cujo comportamento geoquímico é muito parecido com o do

Tabela 8 - Classificação das águas segundo a dureza em $\mathrm{mg} / \mathrm{L}$ como carbonato de cálcio (Custódio \& Llamas 1983)

\begin{tabular}{lc}
\hline Tipo & Teor de carbonato de cálcio $(\mathrm{mg} / \mathrm{L})$ \\
\hline Branda & $<50$ \\
\hline Pouco dura & $50-100$ \\
\hline Dura & $100-200$ \\
\hline Muito dura & $>200$ \\
\hline
\end{tabular}


cálcio e, em linhas gerais, acompanha este elemento. Entretanto, seu teor nas águas subterrâneas é significativamente menor, uma vez que os minerais fornecedores desse elemento são mais estáveis diante do intemperismo químico. No aquífero Barreiras avaliado, o magnésio variou de 0,71 a $2,37 \mathrm{mg} / \mathrm{L}$ com média de $1,46 \mathrm{mg} / \mathrm{L}$.

O sódio é um elemento químico quase sempre presente nas águas subterrâneas, uma vez que seus principais minerais fonte são pouco resistentes aos processos intempéricos, principalmente os químicos. Os sais formados nestes processos são muito solúveis e é de se esperar um enriquecimento gradativo deste metal a partir das zonas de recarga. Nas amostras de água analisadas, o sódio variou significativamente de 6,09 a 22,00 mg/L, com média de $11,31 \mathrm{mg} / \mathrm{L}$. É interessante observar que o maior teor de sódio foi verificado no P5, poço que já apresenta níveis consideráveis de nitrato quando comparado aos demais poços.

O potássio é um elemento químico abundante na crosta terrestre, mas ocorre em pequena quantidade nas águas subterrâneas, pois é facilmente fixado pelas argilas e intensivamente consumido pelos vegetais. O teor médio de potássio nas águas subterrâneas avaliadas foi de $1,37 \mathrm{mg} / \mathrm{L}$.

O ferro é presente em teores baixos nas águas subterrâneas. Sua concentração depende da intensidade de oxidação ou redução que ocorre no sistema, influenciado por fatores físico-químicos tais como $\mathrm{pH}$, Eh, oxigênio dissolvido, $\mathrm{CO}_{2}$, compostos orgânicos e ainda os micro-organismos que podem afetar as condições de $\mathrm{pH}$ e Eh. A presença deste metal é função da origem da água e sua proveniência pode ser a dissolução de rochas ou a transferência através do solo. A litologia da unidade aquífera é um fator condicionante para teores elevados deste elemento nas águas subterrâneas. A média dos resultados analíticos do ferro para as águas do aquífero Barreiras foi de $0,15 \mathrm{mg} / \mathrm{L}$, variando de 0,03 a $0,28 \mathrm{mg} / \mathrm{L}$. Correlacionando os teores de ferro com os de $\mathrm{CO}_{2}$, apresentados na Tab. 2, não foi detectada uma relação direta entre esses dois parâmetros. Assim sendo, depreende-se que nos poços estudados, o teor de $\mathrm{CO}_{2}$ livre isoladamente não constitui um fator determinante nos teores de ferro das águas.

A concentração de bicarbonato nas águas subterrâneas é moderada devido ao efeito de equilíbrio do íon carbonato, mas em certas condições pode atingir concentrações elevadas, principalmente em águas com baixos teores de cálcio e magnésio e em presença de altos teores de gás carbônico dissolvido na água. $\mathrm{O}$ teor médio obtido para esse parâmetro foi de $11,03 \mathrm{mg} / \mathrm{L}$.

O sulfato, em geral, é relativamente solúvel. A sua presença aliada à abundância de íons de hidrogênio tornam a água ácida. A sua concentração pode estar associada a concentração de água de chuva e a decomposição da matéria orgânica do solo. No aquífero Barreiras os teores de sulfato variaram de menos de 1,00 a $17,6 \mathrm{mg} / \mathrm{L}$ com média de 7,37 mg/L.

O cloreto é um composto altamente solúvel e tende a se enriquecer, junto com o sódio, a partir das zonas de recarga das águas subterrâneas. $\mathrm{O}$ cloreto no aquífero Barreiras variou de 9,94 a 23,19 mg/L, com média de $17,12 \mathrm{mg} / \mathrm{L}$.

\section{Diagramas hidroquímicos Para a interpretação} dos dados quanto aos tipos iônicos de água foi utilizado o diagrama hidroquímico de Piper (Hem 1985), no qual foram plotadas as concentrações dos íons principais na água subterrânea: $\mathrm{Na}^{+}, \mathrm{K}^{+}, \mathrm{Ca}^{2+}, \mathrm{Mg}^{2+}$, $\mathrm{Cl}^{-}, \mathrm{HCO}_{3}{ }^{-}$e $\mathrm{SO}_{4}^{2}$; expressos em miliequivalentes por litro (meq/L). Esse diagrama permite caracterizar as águas subterrâneas quanto aos íons dominantes, além de facilitar a interpretação dos processos hidrogeoquímicos que ocorrem no aquífero objeto de estudo.

As águas amostradas do aquífero Barreiras, em sua maioria são cloretadas sódicas, e em menor proporção mistas (Fig. 4). Esses dados mostram, portanto, que a hidroquímica dessas águas é controlada pelas espécies iônicas $\mathrm{Cl}^{-}$e $\mathrm{Na}^{+}$, em concordância com as características das águas subterrâneas de ambiente costeiro.

Para uma melhor visualização e análise dos dados, os diagramas hidroquímicos de Stiff foram distribuídos espacialmente sobre o mapa de fluxo das águas subterrâneas da área de estudo (Fig. 5). Observa-se que o sódio é o cátion mais abundante e o cloreto o ânion mais abundante em solução, essa configuração está relacionada à localização da área nas proximidades da linha de costa, e notadamente, à presença de aerossóis marinhos enriquecidos nesses sais nas águas precipitadas. O caráter predominantemente livre do aquífero Barreiras nesse setor e a presença dos sedimentos eólicos constituindo uma unidade de transferência e recarga ao referido aquífero favorecem a infiltração desses sais em direção às águas subterrâneas.

Correlação dos íons dissolvidos

Na Tab. 9 é

apresentada a matriz de correlação de Pearson para 


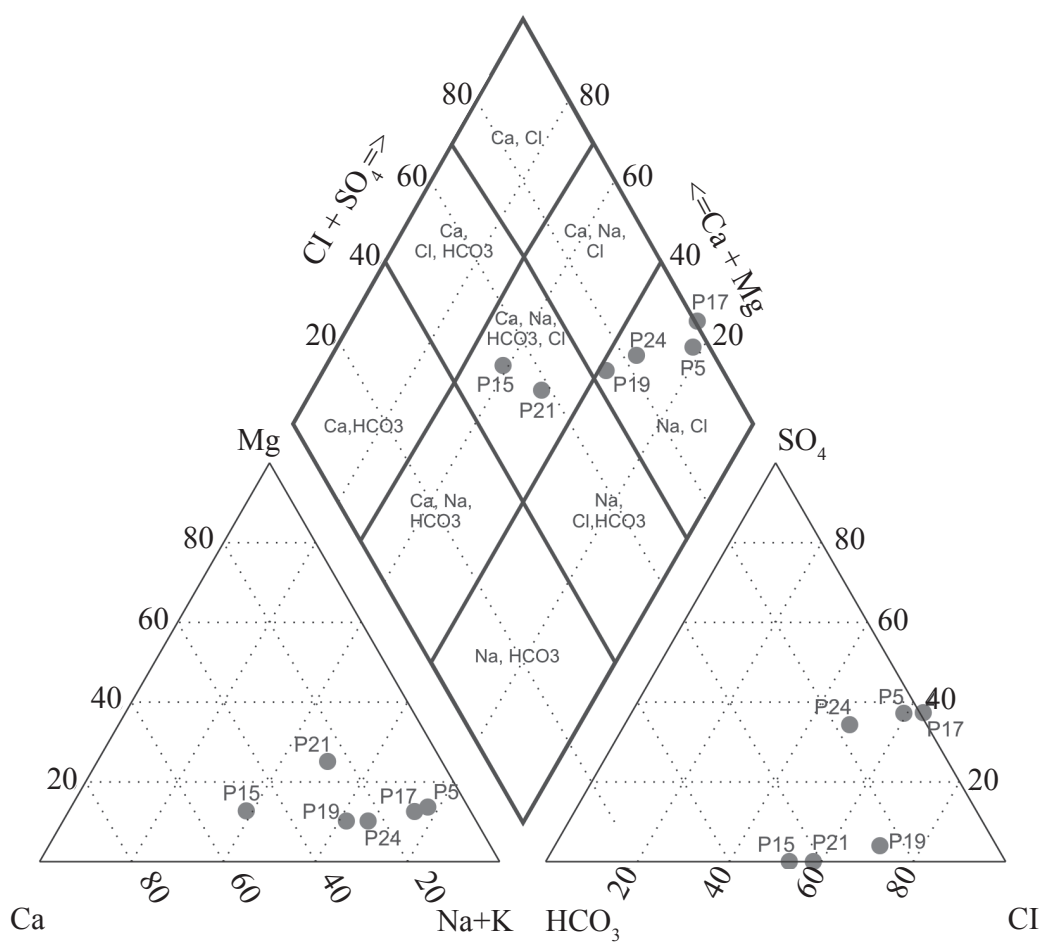

Figura 4 - Diagrama de Piper das águas do aquífero Barreiras nas imediações do Centro de Lançamento da Barreira do Inferno.
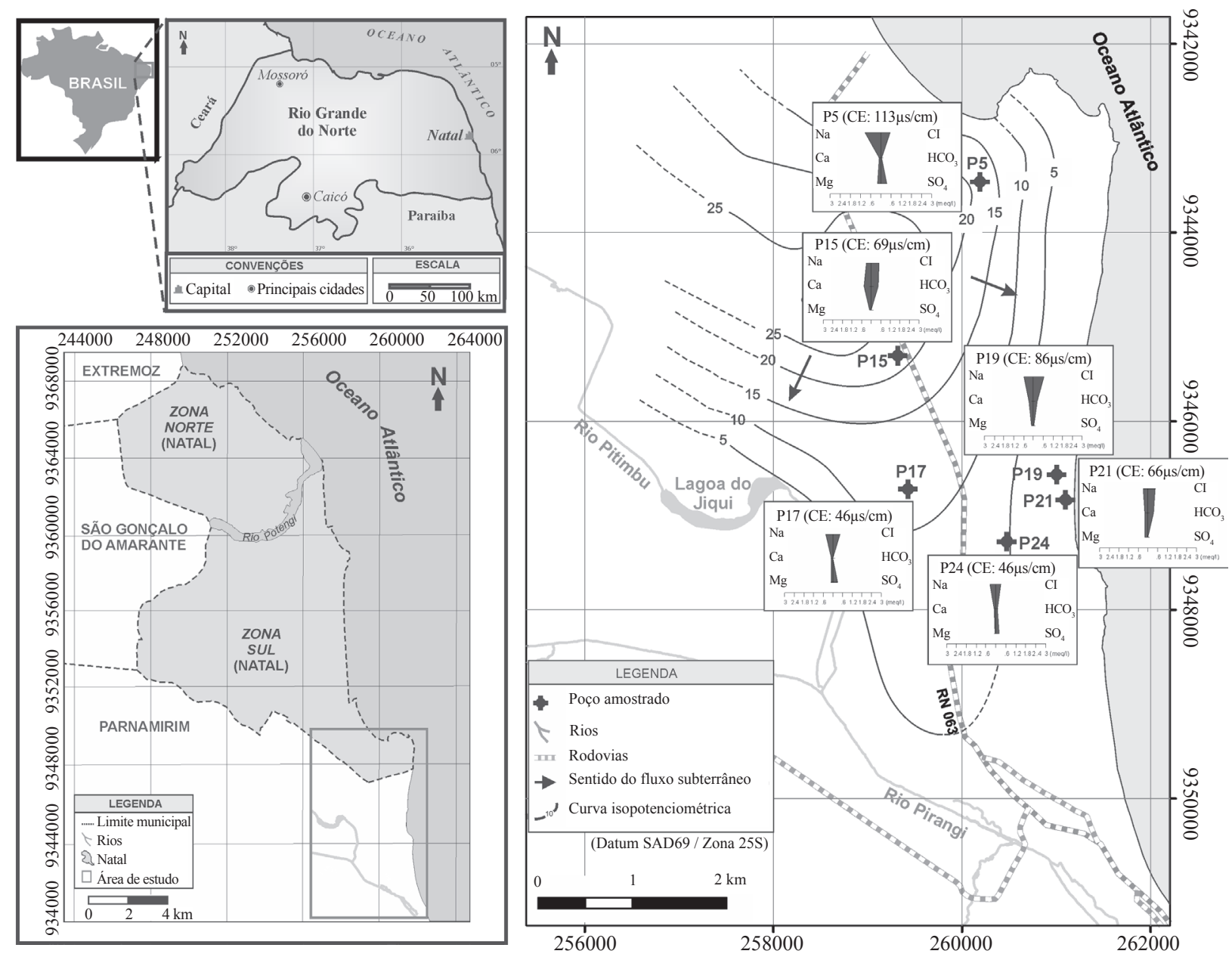

Figura 5 - Fluxo das águas subterrâneas e diagramas de Stiff dos poços amostrados. 
Tabela 9 - Matriz de correlação entre os principais constituintes químicos das águas subterrâneas do aquífero Barreiras na área de estudo

\begin{tabular}{|c|c|c|c|c|c|c|c|c|c|c|c|}
\hline & $\mathrm{CE}$ & SDT & Alcalinidade & $\mathrm{NO}_{3}^{-}$ & $\mathrm{Ca}^{2+}$ & $\mathrm{Mg}^{2+}$ & $\mathrm{Na}^{+}$ & $\mathrm{K}^{+}$ & $\mathrm{Fe}$ & $\mathrm{HCO}_{3}^{-}$ & $\mathrm{SO}_{4}^{2-}$ \\
\hline SDT & 1,00 & & & & & & & & & & \\
\hline Alcalinidade & $-0,02$ & $-0,02$ & & & & & & & & & \\
\hline $\mathrm{NO}_{3}^{-}$ & 0,72 & 0,72 & $-0,49$ & & & & & & & & \\
\hline $\mathrm{Ca}^{2+}$ & 0,08 & 0,08 & 0,88 & $-0,38$ & & & & & & & \\
\hline $\mathrm{Mg}^{2+}$ & 0,60 & 0,60 & 0,32 & 0,38 & 0,04 & & & & & & \\
\hline $\mathrm{Na}^{+}$ & 0,83 & 0,83 & $-0,56$ & 0,88 & $-0,35$ & 0,24 & & & & & \\
\hline $\mathrm{K}^{+}$ & 0,15 & 0,15 & 0,40 & $-0,11$ & $-0,05$ & 0,80 & $-0,22$ & & & & \\
\hline $\mathrm{Fe}$ & $-0,76$ & $-0,76$ & $-0,10$ & $-0,32$ & 0,08 & $-0,74$ & $-0,47$ & $-0,66$ & & & \\
\hline $\mathrm{HCO}_{3}^{-}$ & 0,02 & 0,02 & 1,00 & $-0,47$ & 0,88 & 0,31 & $-0,52$ & 0,40 & $-0,15$ & & \\
\hline $\mathrm{SO}_{4}^{2-}$ & 0,23 & 0,23 & $-0,93$ & 0,73 & $-0,76$ & $-0,11$ & 0,72 & $-0,40$ & 0,06 & $-0,93$ & \\
\hline $\mathrm{Cl}^{-}$ & 0,74 & 0,74 & 0,12 & 0,13 & 0,20 & 0,37 & 0,50 & 0,20 & $-0,78$ & 0,16 & $-0,10$ \\
\hline
\end{tabular}

CE: condutividade elétrica; SDT: sólidos dissolvidos totais

os íons dissolvidos na água subterrânea. A condutividade elétrica é proporcional à quantidade de íons disponíveis na água e reflete o seu conteúdo mineral, portanto, é de se esperar que tenha uma ótima correlação com os sólidos totais dissolvidos. De acordo com a Tab. 9, esses dois parâmetros apresentam correlação perfeita de $r=1,0$.

A condutividade elétrica apresentou boa correlação com os ânions nitrato $(\mathrm{r}=0,72)$ e cloreto $(\mathrm{r}=0,74)$ e com os cátions magnésio $(\mathrm{r}=0,60)$ e sódio $(\mathrm{r}=0,83)$ (Tab. 9), indicando que esses íons são os principais contribuintes da salinidade das águas. Obteve-se, também, uma significativa correlação entre alcalinidade e o cálcio $(r=0,88)$ (Tab. 9), confirmando que a alcalinidade nas águas subterrâneas do aquífero Barreiras na área de estudo deve-se principalmente ao bicarbonato de cálcio.

A boa correlação entre os íons sódio, nitrato e sulfato (Tab. 9) pode indicar a mesma proveniência desses compostos. A contaminação das águas subterrâneas na cidade de Natal por compostos nitrogenados é atribuída à ausência de um sistema de coleta e tratamento de esgotos, que ocasiona a disposição do efluente in situ através de fossas e sumidouros. $\mathrm{O}$ teor de nitrato encontrado nas fossas é baixo e o amônio é alto devido o ambiente redutor do sistema que é mantido pela degradação da matéria orgânica. Entretanto, na medida em que os compostos percolam pelo aquífero em contato com águas mais ricas em oxigênio eleva-se o teor nitrato e o amônio decresce. Na Tab. 10 pode-se visualizar a composição química de dois efluentes domésticos em diferentes locais. A partir desses dados, verifica-se que os íons sódio e sulfato estão em elevadas concentrações, assim como o amônio que posteriormente será oxidado para nitrato.
Tabela 10 - Composição química de efluentes de fossa doméstica no estado de São Paulo e Inglaterra (Robertson, Cherry, Sidicky 1991, Vanier 2001)

\begin{tabular}{lccc}
\hline \multirow{2}{*}{ Parâmetros } & \multirow{2}{*}{ Unidade } & \multicolumn{2}{c}{ Resultado Analítico } \\
\cline { 3 - 4 } & & Cambridge & São Paulo \\
\hline Sódio & $\mathrm{mg} / \mathrm{L} \mathrm{Na}^{+}$ & 98 & 24 \\
\hline Potássio & $\mathrm{mg} / \mathrm{L} \mathrm{K}^{+}$ & 12 & 44,7 \\
\hline Cálcio & $\mathrm{mg} / \mathrm{L} \mathrm{Ca}^{2+}$ & 40 & 16,7 \\
\hline Magnésio & $\mathrm{mg} / \mathrm{L} \mathrm{Mg}^{2+}$ & 14 & 3,15 \\
\hline Cloreto & $\mathrm{mg} / \mathrm{L} \mathrm{Cl}^{-}$ & 45 & 105 \\
\hline Sulfato & $\mathrm{mg} / \mathrm{L} \mathrm{SO}_{4}^{2-}$ & 27 & 24 \\
\hline Nitrato & $\mathrm{mg} / \mathrm{L} \mathrm{N}^{-2}$ & 4,4 & 5,3 \\
\hline Amônio & $\mathrm{mg} / \mathrm{L} \mathrm{NH}_{4}^{+}$ & 38,7 & 77,4 \\
\hline Alcalinidade & $\mathrm{mg} / \mathrm{L} \mathrm{CaCO}_{3}$ & 365 & 336 \\
\hline pH & - & 7,9 & - \\
\hline
\end{tabular}

\section{CONCLUSÕES E RECOMENDAÇÕES}

As águas do aquífero Barreiras no setor estudado tendem a serem cloretadas sódicas. A condutividade elétrica média é de $71,7 \mu \mathrm{S} / \mathrm{cm}$, o que evidencia que em condições naturais são pouco mineralizadas, isto é, apresentam baixa salinidade. No âmbito do estudo as águas do aquífero Barreiras podem ser consumidas pelo homem sem prejuízo para a sua saúde, de acordo com os padrões de potabilidade vigentes.

Entretanto, merece destaque o poço P5 que está localizado em uma área residencial e apresenta teores elevados em alguns parâmetros (condutividade elétrica: $113 \mu \mathrm{S} / \mathrm{cm}$; Na: $22 \mathrm{mg} / \mathrm{L} ; \mathrm{NO}_{3}^{-:}: 4,14 \mathrm{mg} / \mathrm{L} \mathrm{N} \mathrm{e}$ $\mathrm{SO}_{4}^{2-:} 17,6 \mathrm{mg} / \mathrm{L}$ ) quando comparados aos valores obtidos nos demais poços amostrados. Os resultados analíticos não superam os padrões de potabilidade, mas podem evidenciar um processo inicial de alteração da qualidade natural do aquífero pela contaminação por efluentes domésticos dispostos em fossas sépticas, sistema este alternativo em face da deficiência do esgotamento sanitário público na área. 
Para ratificar essa conclusão, recomendam-se novas campanhas de amostragem com análises físico-químicas completas e bacteriológicas, considerando a sazonalidade da região, isto é, em diferentes fases do regime pluviométrico, de modo que venham a ser caracterizadas possíveis mudanças na qualidade das águas entre os períodos seco e úmido.

A boa qualidade das águas subterrâneas caracterizadas nesse estudo indica a possibilidade de aproveitamento futuro no reforço do abastecimento da zona sul de Natal via poços tubulares perfurados no seu domínio. Nesse sentido, é fundamental que o planejamento urbano municipal incentive a preservação da área estudada, contemplando as zonas de recarga do aquífero Barreiras e os sentidos principais de fluxo das águas subterrâneas evidenciados no âmbito do estudo.

AGRADECIMENTOS À Companhia de Águas e Esgotos do Rio Grande do Norte (CAERN) pelo apoio concedido durante a execução do trabalho.

\section{Referências}

AMERICAN PUBLIC HEALTH ASSOCIATION (APHA). 2005. Standard methods for the examination of water \& wastewater. 21st ed. Washington, DC, American Water Works Association and Water Pollution Control Federation.

BRASIL. Ministério Da Saúde. Portaria no 2.914. Brasília. 2011. Dispóe sobre os procedimentos de controle e de vigilância da qualidade da água para consumo humano e seu padrão de potabilidade. Disponível em: http:// portal.saude.gov.br/portal/arquivos/pdf/portaria_2914. pdf. Acessado em: 28/09/2012.

Cabral N.M.T. 2007. Avaliação do comportamento do Aquifero Dunas/Barreiras frente aos processos de recarga $e$ de contaminação em perímetro urbano de Natal/RN. Relatório Técnico de Pós-doutorado, Conselho Nacional de Desenvolvimento Tecnológico e Científico/Universidade Federal do Rio Grande do Norte, Natal. 150p.

Custodio E. \& Llamas M.R. 1983. Hidrologia Subterranea. Barcelona, Ômega, v. 2.

Diniz Filho J.B., Lucena L.R.F., Stein P. 2009. Caracterização da potencialidade hidrogeológica da área do Centro de Lançamento da Barreira do Inferno - CLBI e adjacências, Parnamirim-RN. Relatório técnico FUNPEC/CAERN, Natal. 100 p.

Hem J.D. 1985. Study and interpretation of the chemical characteristics of natural water. 5. ed. Los Angeles, University Press of the Pacific. 384 p.

INSTITUTO DE PESQUISAS TECNOLÓGICAS DO ESTADO DE SÃO PAULO (IPT). 1982. Estudo hidrogeológico regional detalhado do Estado do Rio Grande do Norte. Natal: SIC-Gov/RN, 1982. IPT, Relatório técnico IPT n ${ }^{\circ}$ 15.795. 389 p.

Lucena L.R.F. \& Queiroz M.A. 1996. Considerações sobre as influências de uma tectônica cenozóica na pesquisa e prospecção de recursos hídricos - o exemplo do litoral sul de Natal-RN, Brasil. Revista Águas Subterrâneas, 1(15):81-88.

Lucena L.R.F., Rosa Filho E. F., Bittencourt A.V.L. 2004. A potenciometria do Aquífero Barreiras no setor oriental da bacia do Rio Pirangi-RN e considerações sobre a relação com mananciais superficiais. Revista Águas Subterrâneas, 18:19-27.

McNeely R.N., Neimanis V.P., Dwyer L. 1979. Water quality sourcebook. A guide to water quality parameters. Ottawa, Canadá. $89 \mathrm{p}$.

Melo J.G. 1995. Impactos do desenvolvimento urbano nas águas subterrâneas de Natal/RN - Zona Sul. Tese de Doutorado, Instituto de Geociências, Universidade de São Paulo, São Paulo, 196 p.

RIO GRANDE DO NORTE (estado). Secretaria de Recursos Hídricos do Rio Grande do Norte (SERHID). Fundação de Apoio a Educação e ao Desenvolvimento Tecnológico do Rio Grande do Norte (FUNCERN). 2006. Cadastramento e nivelamento de poços do Aquífero Barreiras no município de Natal/RN: relatório final. Natal, SERHID/FUNCERN.

Robertson W.D., Cherry J.A., Sidicky E.A. 1991. Groundwater contamination from two small septic systems on sand aquifer. Ground water, 29(1):82-92.

Vanier C. 2001. O efeito do nitrogênio provenientes de sistemas de saneamento "in situ" na qualidade das águas subterrâneas em aquiferos livres e rasos. Dissertação de Mestrado, Instituto de Geociências, Universidade de São Paulo, São Paulo, 88p.

Manuscrito ID 17346

Recebido em: 22/04/2010 Aprovado em: 27/06/2012 